University of Nebraska - Lincoln

DigitalCommons@University of Nebraska - Lincoln

Biochemistry -- Faculty Publications

Biochemistry, Department of

2001

Rab11-like GTPase associates with and regulates the structure
and function of the contractile vacuole system in Dictyostelium

Ed Harris

University of Nebraska - Lincoln, eharris5@unl.edu

Kunito Yoshida

Kyoto University, Japan

James Cardelli

LSU Health Sciences Center, Shreveport, LA, jcarde@lsuhsc.edu

John Bush

University of Arkansas at Little Rock,

Follow this and additional works at: https://digitalcommons.unl.edu/biochemfacpub

Part of the Biochemistry, Biophysics, and Structural Biology Commons

Harris, Ed; Yoshida, Kunito; Cardelli, James; and Bush, John, "Rab11-like GTPase associates with and regulates the structure and function of the contractile vacuole system in Dictyostelium" (2001).

Biochemistry -- Faculty Publications. 44.

https://digitalcommons.unl.edu/biochemfacpub/44

This Article is brought to you for free and open access by the Biochemistry, Department of at DigitalCommons@University of Nebraska - Lincoln. It has been accepted for inclusion in Biochemistry -- Faculty Publications by an authorized administrator of DigitalCommons@University of Nebraska - Lincoln. 


\title{
Rab11-like GTPase associates with and regulates the structure and function of the contractile vacuole system in Dictyostelium
}

\author{
Edward Harris ${ }^{1}$, Kunito Yoshida ${ }^{2}$, James Cardelli1 and John Bush ${ }^{3, *}$ \\ 1Department of Microbiology and Immunology, LSU Health Sciences Center, Shreveport, LA 71130, USA \\ 2Department of Botany, Kyoto University, Kyoto 606-8502 Japan \\ ${ }^{3}$ Department of Biology, University of Arkansas at Little Rock, Little Rock, AR 72204, USA \\ *Author for correspondence (e-mail: jmbush@ualr.edu) \\ Accepted 9 May 2001 \\ Journal of Cell Science 114, 3035-3045 (2001) @ The Company of Biologists Ltd
}

\section{SUMMARY}

Screening of a cDNA library revealed the existence of a Dictyostelium cDNA encoding a protein $80 \%$ identical at the amino acid level to mammalian Rab11. Subcellular fractionation and immunofluorescence studies revealed that DdRab11 was exclusively associated with the ATPase proton pump-rich contractile vacuole membrane system, consisting of a reticular network and bladder-like vacuoles. Video microscopy of cells expressing GFP-DdRab11 revealed that this Rab was associated with contractile vacuolar bladders undergoing formation, fusion and expulsion of water. The association of DdRab11 with contractile vacuole membranes was disrupted when cells were exposed to either hypo-osmotic conditions or an inhibitor of the ATPase proton pump. Cells that overexpressed a dominant negative form of DdRab11 were analyzed biochemically and microscopically to measure changes in the structure and function of the contractile vacuole system. Compared with wild-type cells, the dominant negative DdRab11-expressing cells contained a more extensive contractile vacuole network and abnormally enlarged contractile vacuole bladders, most likely the result of defects in membrane trafficking. In addition, the mutant cells enlarged, detached from surfaces and contained large vacuoles when exposed to water, suggesting a functional defect in osmotic regulation. No changes were observed in mutant cells in the rate of fluid phase internalization or release, suggesting the DdRab11mediated membrane trafficking defects were not general in nature. Surprisingly, the rate of phagocytosis was increased in the dominant negative DdRab11-expressing cells when compared with control cells. Our results are consistent with a role for DdRab11 in regulating membrane traffic to maintain the normal morphology and function of the contractile vacuole.

Key words: Dictyostelium, DdRab11, Contractile vacuole

\section{INTRODUCTION}

Vesicular transport is a complex biological process involving the movement of membrane vesicles to and from intracellular compartments. The production, transport and fusion of donor membrane vesicles with an acceptor membrane compartment are regulated by numerous protein factors that work in an organized and specific fashion (Mellman, 1994). One such group of proteins is the Rab family of small molecular weight GTPases that are structurally related to the Ras proteins. The related regions include at least four protein domains found in all GTPases that are involved in the binding of GTP or GDP (Nuoffer and Balch, 1994). When GTPases, including Rabs, are in the GTP-bound state, they are thought to be functionally active and are inactive when they bind GDP (Nuoffer and Balch, 1994). All GTPases undergo a cycle mediated by guanine nucleotide exchange factors and GTPase activating proteins that stimulate exchange of GDP for GTP or stimulate hydrolysis of GTP (Nuoffer and Balch, 1994).

The secretory vesicular pathway originates at the endoplasmic reticulum and passes through the Golgi into lysosomes, secretory granules or the extracellular environment via exocytosis. At least four members of the Rab GTPase family associate with the secretory pathway, including Rab1 (ER to Golgi), Rab3 (exocytosis), Rab6 (Golgi) and Rab11 (secretory granules and endosome; Nuoffer and Balch, 1994; Green et al., 1997; Ren et al., 1998). The other extensively studied vesicle transport pathway is the endocytic pathway by which material from the extracellular environment of the cell can be internalized (endocytosed) and transported through early and late endosomal organelles arriving in the lysosomes (site of intracellular digestion; Nuoffer and Balch, 1994). At least five members of the Rab family have been localized to this pathway, including Rab4, 5 and 11 (early endosomes) plus Rab7 and Rab9 (late endosomes; Nuoffer and Balch, 1994; Green et al., 1997; Ren et al., 1998).

The process of membrane and protein transport has been extensively studied in many systems, including the simple eukaryote, Dictyostelium discoideum. This genetically tractable amoeba shares similarity with human leukocytes in terms of a prominent endocytic pathway and a highly phagocytic nature (reviewed by Rupper and Cardelli, 2001; Maniak, 2001). Extracellular fluid phase material can be endocytosed via a variety of different processes, including micropinocytosis and macropinocytosis. As observed in 
mammalian cells, fluid is transported through endosomes into acidic lysosome-like vesicles in $D$. discoideum (Rupper and Cardelli, 2001; Maniak, 2001). Uniquely in D. discoideum, cargo is then transported from lysosomes to larger neutral postlysosome-like compartments before egestion (Rupper and Cardelli, 2001; Maniak, 2001). The D. discoideum endocytic pathway also differs from mammalian cells in the apparent lack of rapid fluid recycling from early endosomal compartments back to the cell surface, although plasma membrane proteins are rapidly recycled (Neuhaus and Soldati, 2000). In $D$. discoideum, endocytic fluid phase trafficking is linear and extracellular cargo moves through all of the endocytic compartments before leaving the cell (Maniak, 2001).

Like other protozoans, $D$. discoideum has a contractile vacuole (CV) complex that serves to excrete cytoplasmic water and insures survival in a hypo-osmotic environment. The CV complex is enriched in membrane-associated alkaline phosphatase, calmodulin $\left(\mathrm{Ca}^{2+}\right.$-binding protein) and vacuolar proton pumps (V-H-(+) ATPase; Nolta and Steck, 1994). This complex has a bipartite morphology that consists of a bladderlike pump vacuole and an associated tubular spongiomal network (Nolta and Steck, 1994). The CV is the site of water collection in the cell, and excess water is excreted using a myosin-driven contraction that forces water from the vacuole into the extracellular medium (Nolta and Steck, 1994). In contrast to the $\mathrm{CV}$ bladder, the spongiomal network contains little protein other than $\mathrm{V}-\mathrm{H}(+)$ ATPase, which has been predicted to catalyze the primary energy reactions needed to pump water to the vacuole (Heuser et al., 1993; Nolta and Steck, 1994).

In an earlier screen, we isolated 20 members of the Ras superfamily of GTPases from a $D$. discoideum cDNA library (Bush et al., 1993; Daniels et al., 1994; Bush et al., 1994; Hall, 1993; Bush and Cardelli, 1995). Several of the Rab-like GTPases have been further characterized, including two Rab GTPases, RabD (a Rab4 homolog) and Rab7, which are between 70 and $80 \%$ identical at the amino acid level to their human homologs (Bush et al., 1996; Buczynski et al., 1997).

All reported Rab GTPases are thought to function in the processes of eukaryotic vesicular transport and fusion between intracellular compartments or in exocytosis from the cell (Mellman, 1994). Our observation that RabD was localized to the CV complex and endo-lysosomes suggested that an uncharacterized membrane transport system connecting the endo-lysosomal and $\mathrm{CV}$ system exists in $D$. discoideum (Bush et al., 1994). Supporting this idea, we have found that the RabD regulates not only the function of the $\mathrm{CV}$ complex but also the localization of two associated CV complex marker proteins, calmodulin and vacuolar ATPase (V-H(+)ATPase; Bush et al., 1996). Additional experiments revealed that the RabD was also involved in the regulation of the early endocytic pathway in $D$. discoideum (Bush et al., 1994). In this report, we describe the cloning and analysis of a Dictyostelium DdRab11 homologue and demonstrate that this Rab protein, like RabD, also regulates the structure and function of the $\mathrm{CV}$ complex.

\section{MATERIALS AND METHODS}

\section{Organism}

D. discoideum wild-type and DdRab11 N125I-expressing strains were grown axenically in TM broth at $21 \mathrm{C}$ shaken at $120 \mathrm{rpm}$.

\section{Cloning cDNAs}

A standard plaque lift (Sambrook et al., 1989) was used to screen a recombinant cDNA library constructed in lamda gt11, using mRNA prepared from cells that had developed for 4 hours (Bush et al., 1993). Probe design, hybridizations, washing conditions and PCR sequencing of the DNA were as previously described (Bush et al., 1993).

\section{Antibody production}

The DdRab11 cDNA was ligated directionally into the pRSET bacterial expression vector and used to generate affinity-purified protein suitable for immunization of New Zealand male rabbits (Cocalico Biologicals). Specific DdRab11 antibodies were isolated and tested for crossreactivity to other Dictyostelium Rab proteins (DdRab2, DdRabD, and DdRab7) by Western Blot analysis (Bush et al., 1994).

\section{Subcellular fractionation}

Membrane fractionation of Ax4 cells was performed as described previously (Bush et al., 1994). The resulting crude and high-resolution membrane fractions were subjected to SDS-PAGE and western blot analysis, as described below in the western blot analysis section. Magnetic fractionation of Ax4 cells has also been detailed before (Rodrigeuz-Paris et al., 1993).

\section{Western blot analysis}

Proteins were separated by SDS-PAGE and transferred to nitrocellulose. Blots were then probed with Rabbit serum primary antibodies to DdRab11 (Bush et al., 1994) washed, incubated with goat anti-rabbit secondary antibody conjugated to alkaline phosphatase (Sigma) and visualized using Sigma FAST tablets (Sigma).

\section{Immunofluorescence microscopy}

Both wild-type and mutant cells were allowed to settled onto plastic coverslips, fixed, and probed with primary and secondary antibodies (Bush et al., 1994). Stained cells were photographed using an Olympus model BH-2 fluorescence microscope and Kodak T-Max 400 speed film.

\section{Molecular techniques}

The DdRab11 cDNA was subjected to oligonucleotide-mediated sitedirected mutagenesis in order to change a key amino acid asparagine (N) to isoleucine (I) at amino acid position 125 in the predicted open reading frame of the DdRab11 gene. The mutated cDNA was then sequenced to confirm the single change in the DdRab11 protein. The mutant DdRab11 cDNA was placed into a Dictyostelium expression vector pHA80 and wild-type cells were transformed. Proteins expressed from this vector are constitutively expressed as fusions inframe with an $\mathrm{N}$-terminal $\mathrm{HA}$ amino acid tagged epitope, detectable by a monoclonal antibody (Bush et al., 1996).

\section{GFP DdRab11 expression}

The complete Dictyostelium DdRab11-coding region cDNA (Bush et al., 1994) was modified with the addition of BamHI recognition site DNA at the end of the DdRab11 cDNA and the addition of XbaI SacI recognition site DNA at the beginning of the DdRAB cDNA using oligonucleotide mediated PCR. The resulting PCR product was ligated into the TA vector (Invitrogen) and sequenced for both errors and confirmation for the presence of the N-terminal XbaI SacI sites and C-terminal BamHI sites. The DdRab11 PCR TA product was then digested with $B a m \mathrm{HI}$ and $\mathrm{XbaI}$, purified and ligated into the pDXAHC vector previously cut by BamHI and XbaI (Manstein et al., 1995). This new construct pDdRab11DXA-HC was then sequenced for errors before the next ligation step.

DNA encoding green fluorescent protein (GFP) was modified by the addition of KpnI N-terminal and SacI C-terminal via 


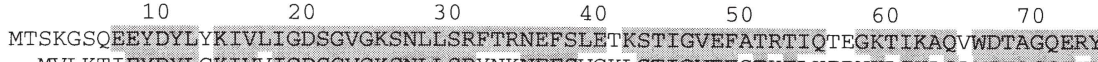

DaRab11 DaRab11b H. Rab11 S. P. YPT3 H. Rab25

Fig. 1. Sequence alignments an Southern and northern blots of DdRab11. The nucleotide sequence of the DdRab11 gene was analyzed using MacVector software of IBI and the putative protein sequence is shown. The amino acid sequence for the Dictyostelium Rab11b, the human Rab11, human Rab25, and the yeast protein, YPT3, are also shown. Optimum amino acid alignment is shown in the figure.
DdRab11 DaRab11b H. Rab11 S.P. YPT3 H. Rab25

DaRab11 DdRab11b H. Rab11 S.p. YPT3 H. Rab25 -MVLKTIEYDYLCKIVVIGDSGVGKSNLLSRYNKNEFSVGKLSTIGVEFSTKTLKIDNKLIKLQLWDTAGQEKY -MGTRDDEYDYLFKVVLIGDSGVGKSNLLSRFTRNEFNLESKSTIGVEFATRS IQVDGKTIKAOIWDTAGOERY - --MCQEDEYDYLFKTVLIGDSGVGKSNLLMRFTRNEFNIESKSTIGVEFATRNIVLDNKK IKAQIWDTAGOERY -MGNGKEEDYNFVFKVVLIGESGVGKTNLLSRFTRNEFSNDSRTTIGVEFSTRTVLLGTAAVKAQIWDTAGLERY

$$
80
$$

$$
90
$$

100

110

$$
120
$$$$
130
$$

140 150

SAYYRGAVGALLVYDIAKOATYKSVERWILELRENADRNIEIMLVGNKSDLRHLREVSTDEAKEF SEKHKI NSITESYYKGAIGALIVYNIADRNSFNNLEKWLKKFRENAHQDYGIMLVGNKSDLKEYREVSTLEGKQFAEKHYM RAITSAYYRGAVGALLVYDIAKHLTYENVERWLKELRDHADSNIVIMLVGNKSDLRHLRAVPTDEARAFAEKNGL RAITSAYYRGAVGAL I VYDITKQSSF DNVGRWLKELREHAD SNIVIMLVGNKTDLLHLRAVSTEEAQAFAAENNL RAITSAYYRGAVGALLVFDLTKHQTYAVVERWLKELYDHAEATIVVMLVGNKSDLSQAREVPTEEARMFAENNGI

$$
\begin{array}{llllr}
160 & 170 & 180 & 190 & 200
\end{array}
$$
QFI ETSALDSNNVETAFNNLFNF IYYSLFKNKTMTLDINNNGNNNSN--IMVGDCEPIQFDQRYTINKPVYDCC SFIETSALDSTNVEAAFOTILTEIYRIVSOKOMSDRRENDMS PSNNVVPIHVP - - PTTENK-P- -KVQ- - - CC SFIETSAMDASNVEEAFQTVLTEIFRIVSNRSLEAGDDGVHPTAGQTLNIA-- - PTMNDLNKK KSSSQ--CC LFLETSALDSTNVELAFETVLKEIFAKVSKQIQNSPRSNA IALGSAQAGQ--.-.---EPGPGQKRA---.CC oligonucleotide mediated PCR. The resulting PCR product was subcloned in the TA vector and sequenced for errors and confirmation of KpnI and SacI recognition site presence. The modified GFP DNA was then digested with $K p n I$ and $S a c I$ and ligated into the pDXA-HC DdRab11 vector, previously cut with $S a c \mathrm{I}$ and $K p n \mathrm{I}$, and purified. This vector construct DdRab11 GFP was sequenced for errors and reading frame conformation. The DdRab11 GFP plasmid and the pREP plasmid (ORF helper plasmid; Manstein et al., 1995), were then cotransformed into Dictyostelium cells as previously described (Bush et al., 1996) and properly expressing cells selected via use of G418 antibiotic selection.

\section{RESULTS}

\section{Dictyostelium DdRab11 associates with the contractile vacuole system}

The 769 nucleotide sequence of one of the cDNAs cloned in a screen for Dictyostelium GTPase encoding cDNAs (National Biomedical Research Foundation Accession Number, U02925) contained one open reading frame (ORF) beginning with an ATG codon at nucleotide position 67 and ending with a TAA stop codon at nucleotide position 711 . The deduced amino acid sequence contained all four of the highly conserved regions (Fig. 1) found in other small GTPases. A BLAST-based search of the protein databases revealed that the amino acid sequence encoded by this cDNA had the greatest homology to the human Rab11, Rab25 and yeast Ypt3 genes, approx. 80\% amino acid identity from positions 8 to 170 (Fig. 1). By contrast, the previously identified Dictyostelium Rab11b was only $62 \%$ homologous to this cDNA. In addition, the potential effector domain for hRab11 and yeast Ypt3 was also highly conserved in the Dictyostelium DdRab11 protein, starting at position number 40 , when compared with the amino acid sequence found in Rab25 or DdRab11b. Therefore, we named the protein DdRab11 to distinguish it from a previously described Rab11like protein named Rab11b (Dragoi and O'Halloran, 1998).

Southern blot analysis using the DdRab11 cDNA as a probe under low stringency hybridization conditions revealed that Dictyostelium DdRab11 was related in sequence to at least one other gene (results not shown). Northern blot analysis using the same cDNA probe detected a single message at $0.8 \mathrm{~kb}$ whose steady state levels remained constant throughout the developmental cycle of this organism (results not shown).

Western blot analysis using an affinity purified rabbit antibody to DdRab11 revealed a single protein of $24 \mathrm{kDa}$ in

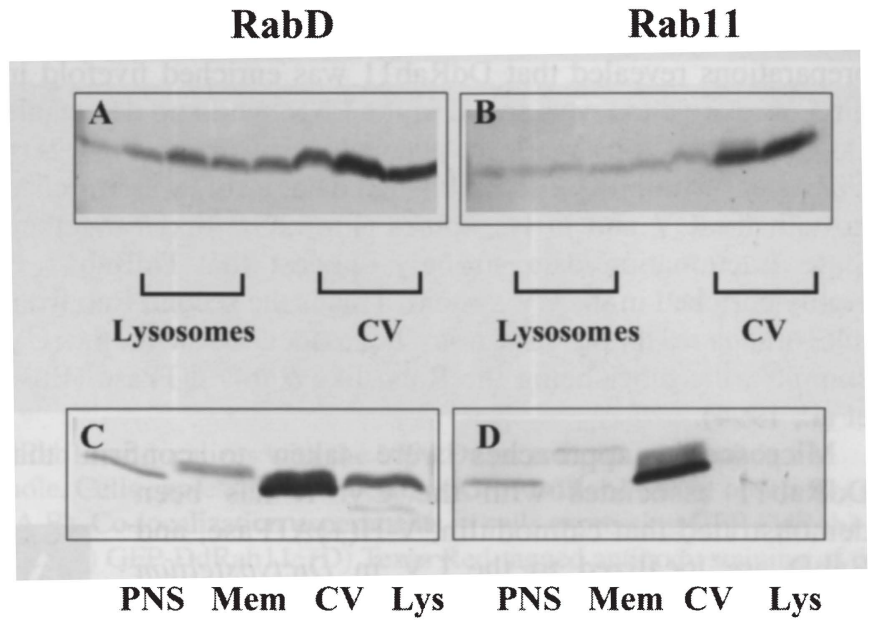

Fig. 2. Dictyostelium DdRab11 is associated with contractile vacuole membranes.(A,B) Post-nuclear extracts prepared from homogenized cells were fractionated on Percoll gradients as described in Materials and Methods. After fractionation, samples were subjected to SDSPAGE followed by western blot analysis using antibodies to DdRab11 and RabD. DdRab11 protein was confined to the top fractions of the gradient that corresponded to non-lysosomal membranes vesicles. Bottom fractions represent lysosomal membrane fraction that contained lysosomal marker enzymes. (C,D) Protein samples $(20 \mu \mathrm{g})$ from post-nuclear supernatant (PNS), purified contractile vacuole (light membranes) and purified lysosomes were subjected to SDS-PAGE and western blot analysis. DdRab11 and RabD were both enriched in contractile vacuole membranes, but only RabD was enriched in purified lysosomes.

total cellular proteins consistent with the predicted molecular weight for this protein (Fig. 2); this band was not observed when preimmune serum was used. In addition, the DdRab11 antibody did not crossreact with either Rab7 or RabD.

Western blot analysis revealed that $95 \%$ of the DdRab11 protein was associated with total cell membranes after centrifugation of cell homogenates. Next, subcellular fractionation experiments were carried out to determine which membrane system DdRab11 associated with. First, post-nuclear supernatants were fractionated on percoll gradients and the separated fractions were subjected to SDSPAGE and western blot analysis. Marker enzyme activities for both the light fractions and lysosomal fractions were determined, and corresponding fractions were grouped as 
shown in Fig. 2A,B. DdRab11 was found to be mainly associated with buoyant membrane fractions that contained endosomes and elements of the $\mathrm{CV}$, while relatively little DdRab11 was found in the dense lysosomal fractions of the gradient (Fig. 2). In contrast, RabD distributed in two peaks on the Percoll gradients. The majority of RabD distributed in the region of the gradient containing the $\mathrm{CV}$ membranes while the remainder was found in the region containing lysosomes. This distribution is consistent with the known association of RabD with both of these membrane systems (Bush et al., 1994; Bush et al., 1996).

The next fractionation scheme involved both magnetic separation to purify lysosomes (Rodrigeuz-Paris et al., 1993) and sucrose density gradients to purify the CV system of membranes. Lysosomal fractions were purified from cells pulsed with colloidal iron for 15 minutes and chased for 30 minutes. Western blot analysis of these lysosomal and CV preparations revealed that DdRab11 was enriched fivefold in the CV relative to levels found in the PNS, while no detectable DdRab11 was observed in purified lysosomes (Fig. 2D). Consistent with previously published data, RabD was enriched in both the CV and in lysosomes (Fig. 2C). Taken together, these fractionation data strongly suggest that DdRab11 is highly enriched in the CV system. This is the second Rab from this organism to be shown to be associated with the CV complex, the other being the Rab4-like RabD GTPase (Bush et al., 1994).

Microscopic approaches were taken to confirm that DdRab11 associates with the CV. It has been demonstrated that calmodulin, $\mathrm{V}-\mathrm{H}(+)$ ATPase, and RabD are localized to the $\mathrm{CV}$ in Dictyostelium (Heuser et al., 1993; Zhu et al., 1993; Bush et al., 1994). Immunofluorescence microscopy (IF) was used to determine whether DdRab11 co-localized with either of these established $\mathrm{CV}$ marker antigens. Fig. 3 shows the results of these colocalization studies, in which detergent permeablized cells were incubated with mouse monoclonal antibodies to the $100 \mathrm{kDa} \mathrm{V}-\mathrm{H}(+)$ vacuolar ATPase subunit and affinity-purified rabbit polyclonal antiserum to DdRab11 or RabD. Cells were then washed and incubated with secondary antibodies coupled with rhodamine (goat anti-rabbit) and fluorescein (goat anti-mouse). DdRab11 (Fig. 3A) was associated with a reticular network of membranes that contained the proton pump (Fig. 3B); DdRab11 also co-localized with RabD. In addition, as previously reported, RabD (Fig. 3C) and the proton pump (Fig. 3D) colocalized to this reticular network (Bush et al., 1994). Thus, we conclude that DdRab11, RabD and the proton pump are all found in the same membrane system, namely the CV network.

To rule out the slight possibility that the DdRab11 antibody was crossreacting with a related Rab11-like protein, we examined the distribution of DdRab11 tagged at the $\mathrm{N}$ terminus with GFP. Fig. 4 shows that GFP-DdRab11 distributes in a reticular network of membranes (Fig. 4A,B) that appeared identical to that of the proton pump detected by immunofluorescence microscopy (Fig. 4C-E).

\section{GFP-tagged DdRab11 associates with the CV network, fusing bladders and bladders undergoing expulsion of water}

Fig. 5 represents an example of real time movie images of cells expressing GFP-DdRab11 in a photographic sequence lasting for 12 seconds. Each image of this sequence (images 1 through 12) represents 1 second of elapsed time. As can be seen in these images, GFP-DdRab11 is associated with a very dynamic CV network connected to vacuoles, comparable with the images observed previously (Gabriel et al., 1999). A very prominent vacuole at the lower bottom (6 o'clock position) can be seen in the images labeled 1 to 12 to be undergoing the process of water expulsion. Notice that DdRab11 remained associated with this structure even after expulsion (image 11 and 12). This vacuole also apparently began to lose connection with the $\mathrm{CV}$ complex just before expulsion (images 5-10), as has been previously suggested (Heuser et al., 1993).

Fig. 6 is another example of movie images of GFP DdRab11 in a photographic sequence lasting for 12 seconds (images 1 through 12) with each image representing about 1 second of elapsed time. Images 3 and 4 of this figure document an apparent homotypic fusion event between two adjacent $\mathrm{CV}$ elements. In image 3 , the white arrowhead indicates the area of fusion between two CV elements beginning in image 2 and completed in image 4 . The size of this large vacuole appeared to decrease in size, possibly owing to the formation of a second adjacent $\mathrm{CV}$ as seen in images 8-11.

Images in Fig. 6 also show the formation of a GFP-Rab11-
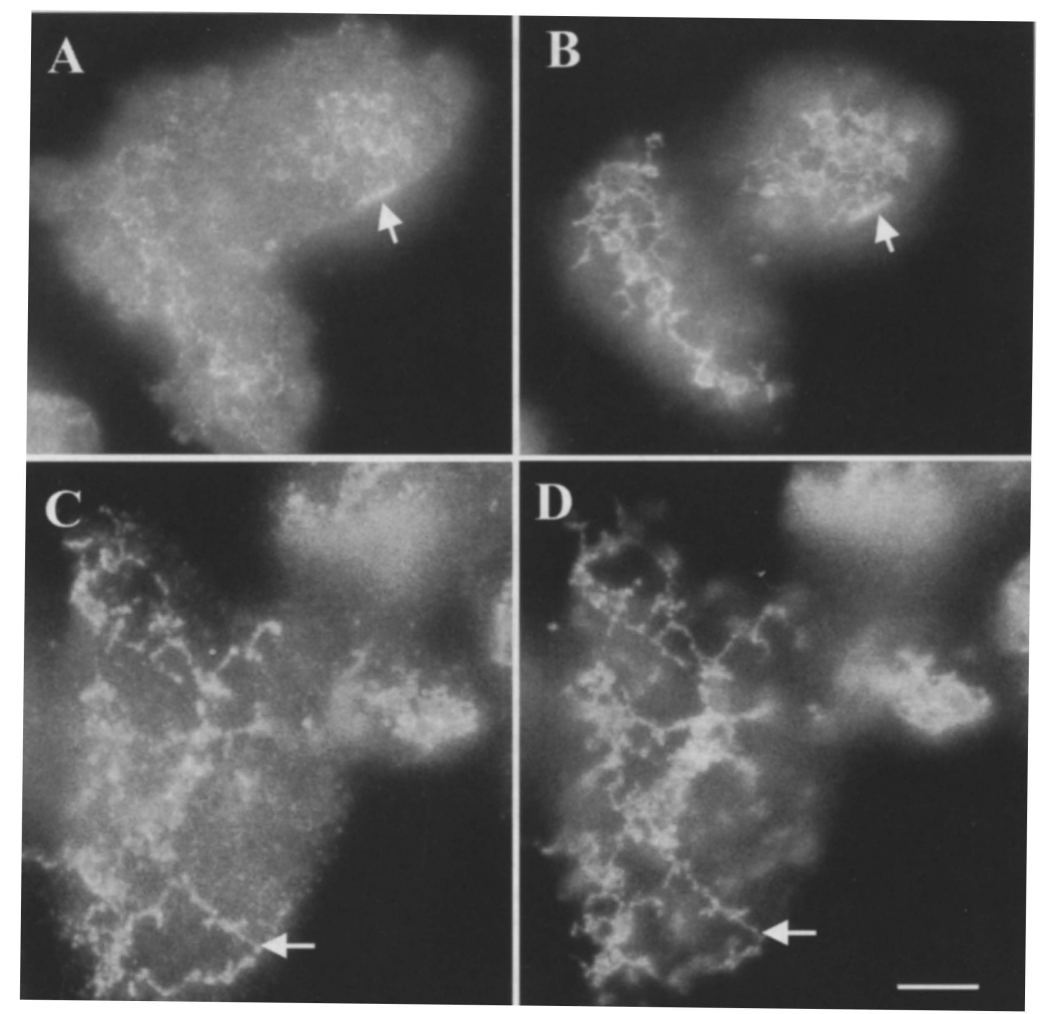

Fig. 3. DdRab11 co-localizes with the $100-\mathrm{kDa}$ vacuolar ATPase in the contractile vacuole. Indirect immunofluorescence techniques were used to stain and visualize fixed cells for DdRab11 (A), ATPase (B,D) and RabD (C). Arrows denote reticular elements that contain DdRab11, RabD, and the $100 \mathrm{kDa}$ proton pump subunit. Scale bars: $5 \mu \mathrm{m}$. 
positive CV bladder. Beginning in image 1, the GFP-DdRab11 stained CV network, as marked by the dashed circle, shows a region of the network that is transformed into a $\mathrm{CV}$ bladder. Moving to image 4 , one sees the apparent formation of an irregular round 'filled in' structure that slowly rounds into a more recognizable bladder by images 10 through 12 . The size of the bladder also increases during this time. This rounding and size increase probably corresponds to the filling of water into this structure.

Finally, as seen in image 1 of Fig. 6, two CV bladders (marked with double arrows) are beginning the process of water expulsion. Following these CVs through the first seven images demonstrates that the network is released from them, followed by an almost simultaneous water expulsion event (see double arrows). The GFP DdRab11-positive membrane remnants then seem to form small vesicles, most likely at the cell surface, which may rejoin the network.

\section{Different osmotic conditions differentially effect the subcellular localization of DdRab11 and other CV proteins}

RabD, DdRab11, calmodulin and the proton pump all co-localize to the $\mathrm{CV}$ network of membranes in cells in normal growth medium (HL5). To determine if the intracellular location of any of these proteins changed in cells osmotically challenged, cells were collected by centrifugation and resuspend in hyperosmotic (100 $\mathrm{mM}$ sucrose in HL5) or hypoosmotic medium (10 mM phosphate buffer) for 1 hour. Cells were spotted on coverslips for 10 minutes and then processed for immunofluoresence microscopy.
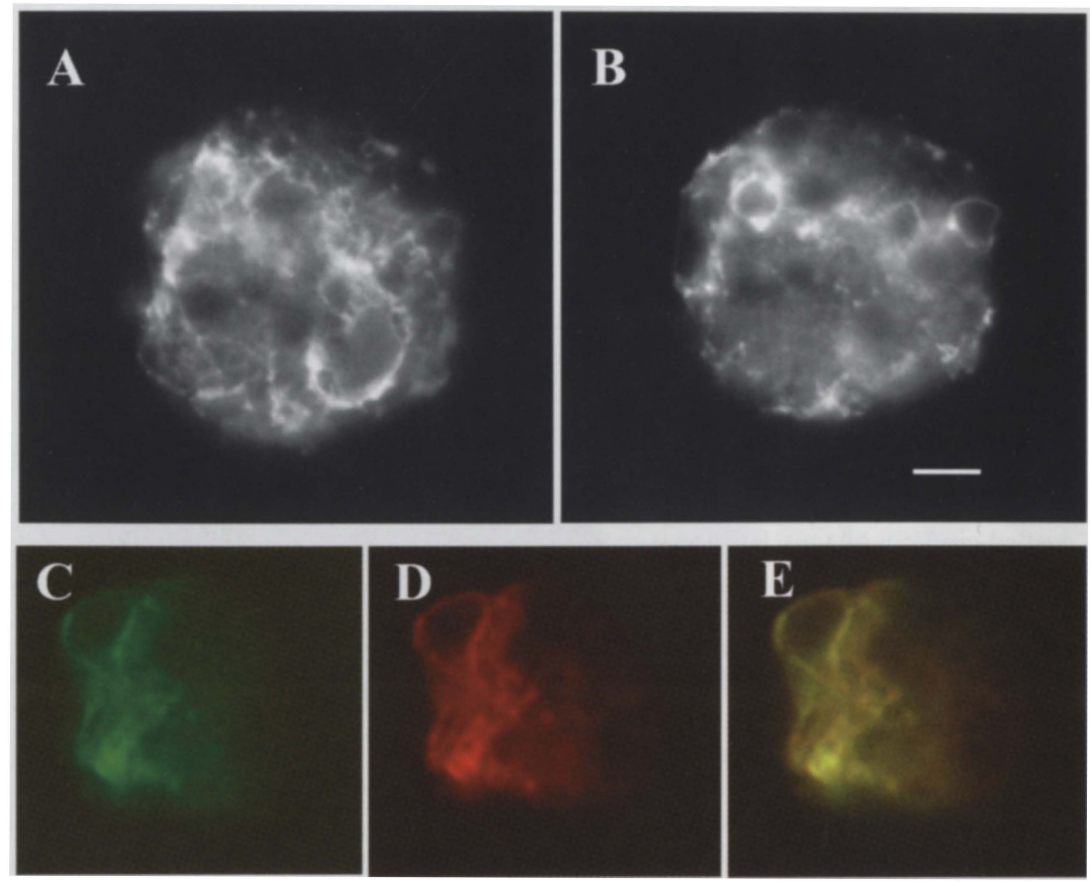

Fig. 4. GFP-DdRab11 co-localizes with the $100 \mathrm{kDa}$ proton pump subunit in the contractile vacuole. Cells expressing CV-localized GFP-DdRab11 were observed and photographed (A,B). Co-localization experiments in cells expressing GFP-DdRab11 are shown in C-E. (C) GFP-DdRab11; (D) Texas Red-tagged antibody staining of the $100 \mathrm{kDa}$ ATPase proton pump protein. (E) A dual fluorescent image of both C,D that demonstrates complete co-localization of GFP-DdRab11 and the $100 \mathrm{kDa}$ ATPase proton pump protein. Scale bar: $5 \mu \mathrm{m}$.
Fig. 5. GFP-DdRab11 associates with expulsing contractile vacuoles. Images 1-12 represent a photographic sequence from a 12 second movie of unfixed cells expressing GFP-DdRab11. The sponguimal network and bladders are easily visualized by the GFP-tagged DdRab11. The $\mathrm{CV}$ at the six o'clock position is shown in the process of water expulsion.

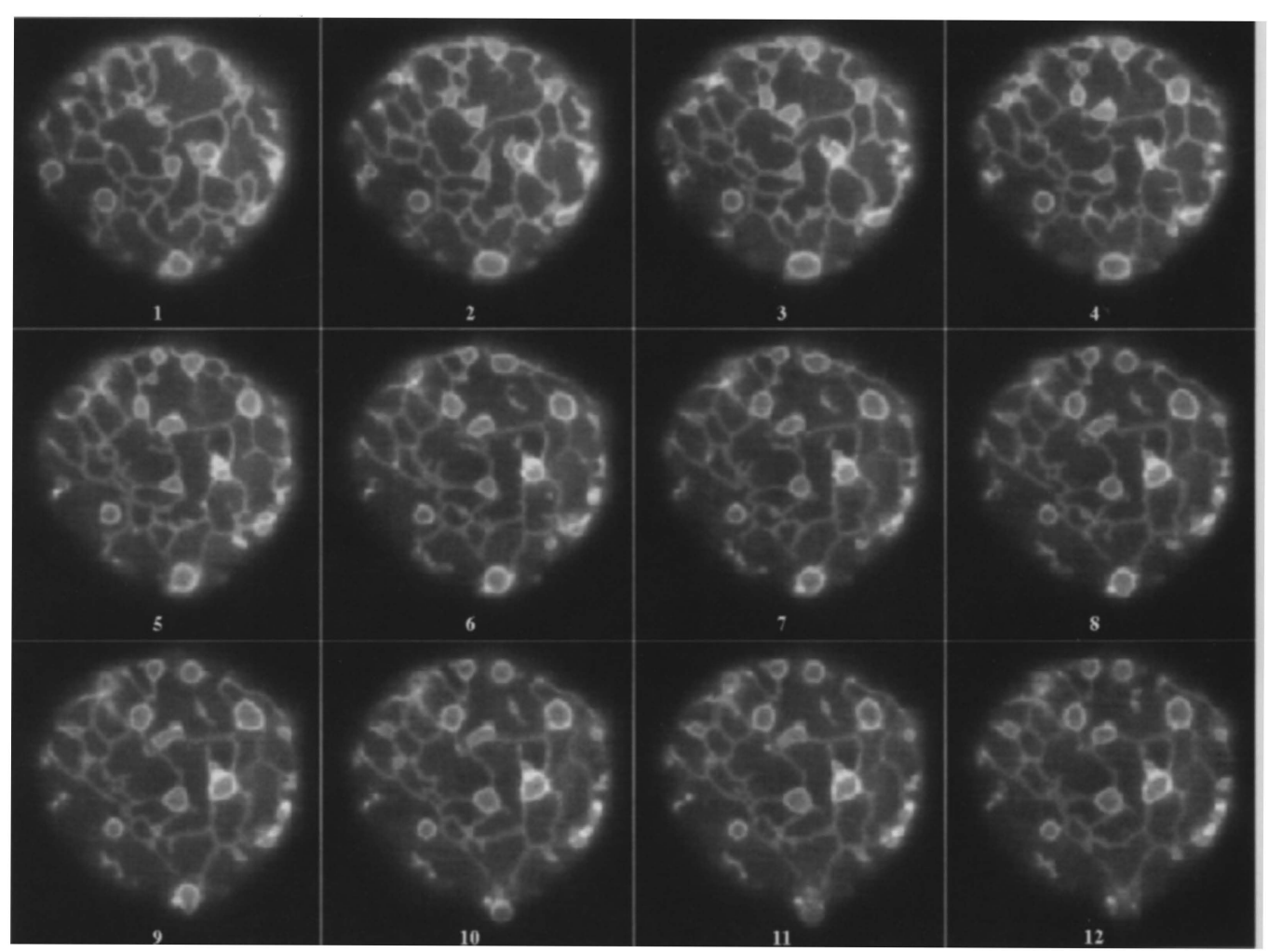


Fig. 6. GFP-DdRab11 is associated with newly forming $\mathrm{CV}$ bladders and $\mathrm{CV}$ bladders undergoing homotypic fusions. Images $1-12$ represent a photographic sequence from a 12 second movie of unfixed cells expressing GFP-DdRab11. The dashed circle in images 1,4 and 9 show the progression of a newly forming CV. The arrowheads in images 3,4 and 8 show a homotypic fusion event between two $\mathrm{CV}$, while in image 11 , the fusion enlarged $\mathrm{CV}$ is shown to have split back into two smaller CVs. In addition, the double arrows in images 2 and 7 show two CVs undergoing water expulsion and network disengagement.

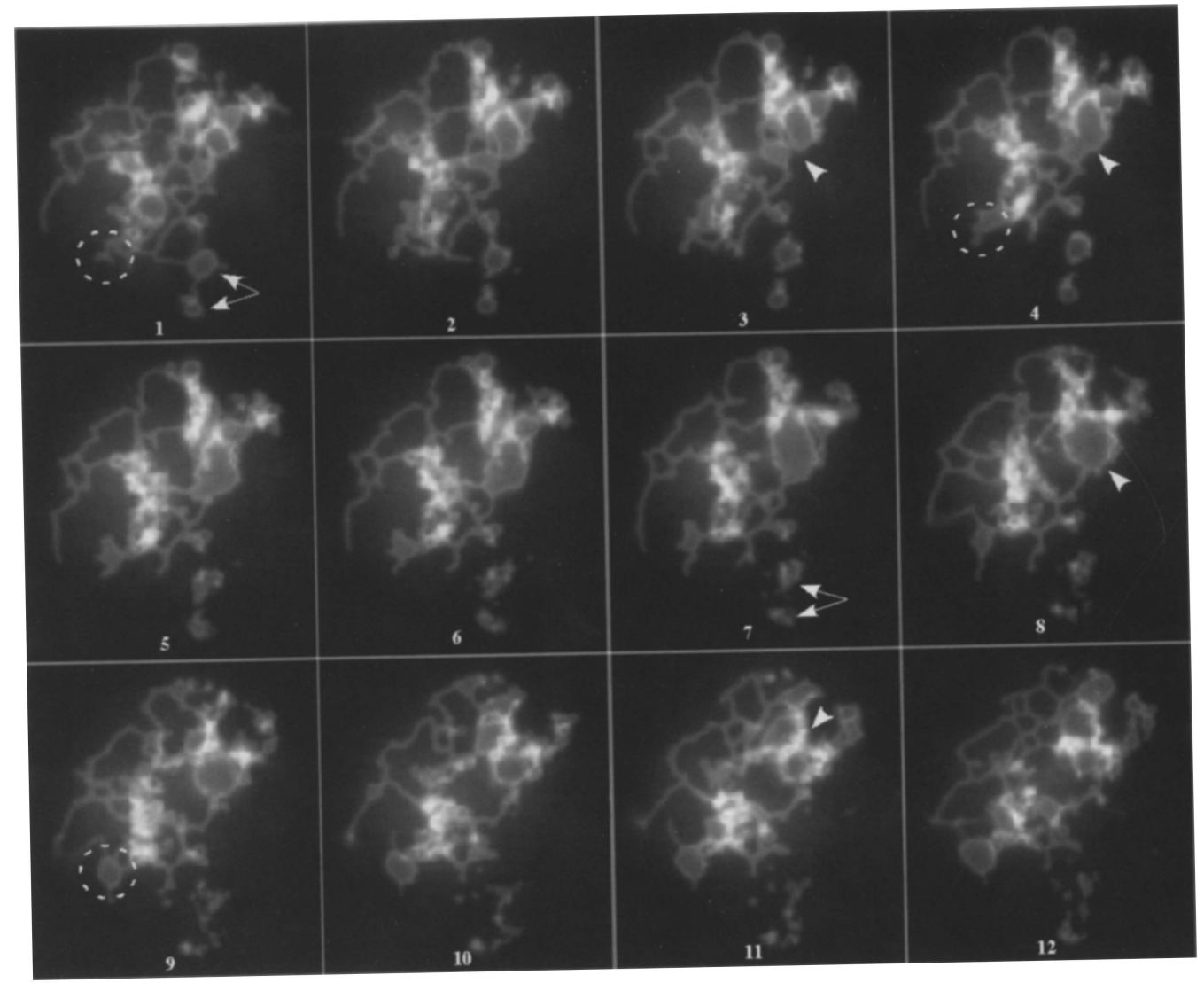

Cells exposed to $100 \mathrm{mM}$ sucrose in HL5 accumulated large endosomal vesicles ringed with Rab7 (Buczynski et al., 1997). Under these conditions, DdRab11 remained associated with the reticular network and continued to co-localize with calmodulin (Fig. 7A,B, respectively). RabD and calmodulin also remained co-localized in the CV under hyper-osmotic conditions (Fig. $7 \mathrm{C}, \mathrm{D}$, respectively). Surprisingly, the proton pump $100 \mathrm{kDa}$ subunit no longer co-localized with DdRab11 in the CV, but instead accumulated in small vesicular structures (Fig. 7E,F). The vesicles (denoted by the arrow in Fig. 7F) are not part of the endosomal pathway (Buczynski et al., 1997).

In cells exposed to hypo-osmotic conditions (100\% water), DdRab11 no longer co-localized with the proton pump (Fig. $8 \mathrm{C}$-E). Under these conditions, the proton pump was found to distribute in swollen CV bladders and residual reticular membranes in many cells (Fig. 8 D,E, marked with an

Fig. 7. DdRab11 co-localizes with the calmodulin and RabD, but not the $100 \mathrm{kDa}$ proton pump subunit in cells exposed to hyper-osmotic conditions. Cells growing on coverslips in HL5 were exposed to sucrose $(100 \mathrm{mM})$ in HL5 for 1 hour. Cells were fixed with formaldehyde and decorated with antibodies to DdRab11 (A,E), $\operatorname{RabD}(\mathrm{C})$, calmodulin $(\mathrm{B}, \mathrm{D})$ and the proton pump subunit $(\mathrm{F})$. Cells were visualized using a fluorescence microscope. White arrows denote a contractile membrane structure that contains DdRab11 and calmodulin proteins (A,B) and RabD and calmodulin (C,D). DdRab11 protein was found in reticular contractile vacuolar membranes when compared with the ATPase-positive vesicular structures accumulating in cells exposed to hyper-osmotic conditions. The white arrow shows the ATPase-positive DdRab11negative region $(\mathrm{F})$. Scale bar: $5 \mu \mathrm{m}$.
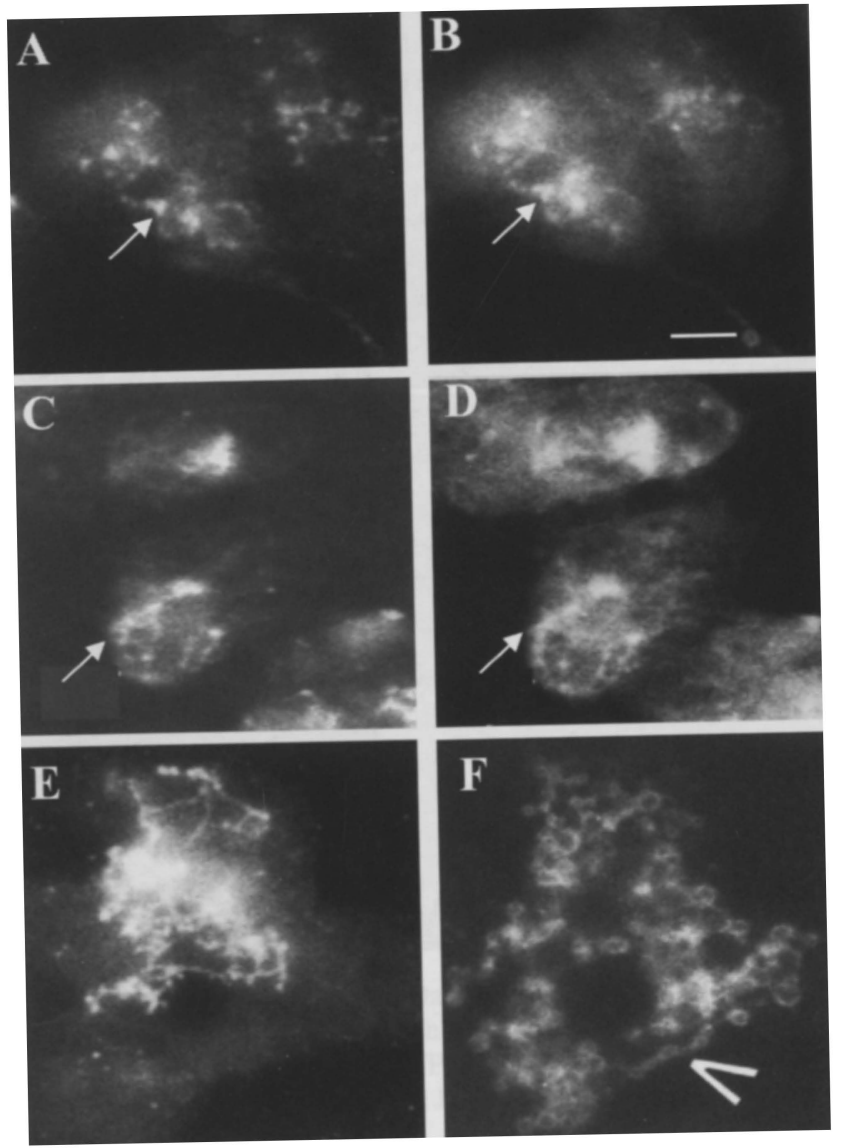
arrowhead). By contrast, DdRab11 was distributed in a diffuse punctate pattern with an accumulation of puncta at the cell surface (Fig. 8C, marked with an arrowhead), while RabD remained co-localized with the proton pump (Fig. 8A,B). The focal plane imaged in Fig. 8A,B reveal predominately a network, although other focal planes in this cell contained vesicles like those observed in Fig. 8D.

Inhibition of proton pump activity by concanamycin A results in an increase in endosomal $\mathrm{pH}$ and accumulation of swollen endo-lysosomes (Temesvari et al., 1996). Under these conditions, the proton pump was found to localize primarily in these large endo-lysosomal vacuoles (Fig. 9B,C, arrow), while DdRab11 (Fig. 9A) distributed in a diffuse punctate pattern with no accumulation of at the cell surface. RabD also did not co-localize with the proton pump under these conditions (compare Fig. 9D with 9E, arrows). These results suggest that two Rab GTPases, RabD and DdRab11, are not unconditionally co-localized with each other or the proton pump, supporting the hypothesis that the GTPases regulate unique membrane trafficking steps in different subcompartments of the CV system.

\section{Generation of stable cell lines overexpressing DdRab11 N125I}

To begin to determine the function of DdRab11 in Dictyostelium, an asparagine was changed to an isoleucine at amino acid position 125 by sitedirected mutagenesis. This amino acid plays a crucial role in the binding of GTP and GDP, and comparable mutations in other Rab proteins result in the formation of proteins that function in a dominant negative manner (Nuoffer and Balch, 1994).

The mutated cDNA was subcloned behind and inframe with DNA encoding the HA flu epitope; Nterminal epitope tagging has been shown not to effect the location and function of this small molecular weight GTPase (Bush et al., 1994). Expression of dominant negative DdRab11 (DdRab11N125I) was under the control of the actin 15 promoter that is constitutively active in axenically growing cells. Wild-type cells were transformed with this plasmid and several G418 resistant clones were isolated. Western blot analysis of these clones was performed and the results showed that transformed cells contained both a $24 \mathrm{kDa}$ wild-type DdRab11 protein as well as a $25 \mathrm{kDa}$ HA-tagged mutated version of the DdRab11 GTPase, as confirmed by decoration with HA-specific antibodies (J.C. and J.B., unpublished). Clones that had at least 2-fold overexpression of the HA-tagged DdRab11 were then selected for further study.

\section{Morphology and function of the contractile vacuole system is altered in cells expressing dominant negative DdRab11}

Expression of dominant negative form of RabD resulted in the redistribution of ATPase-positive $\mathrm{CV}$ membranes into a patch of vesicles at the cell surface

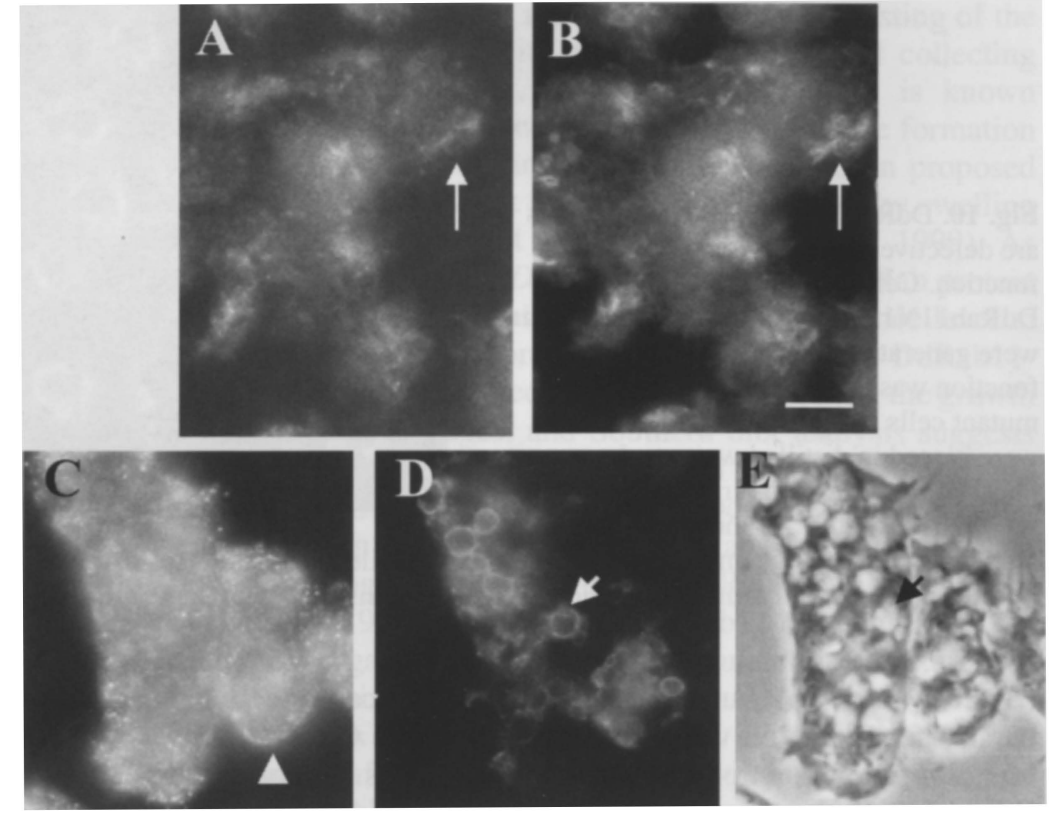

Fig. 8. DdRab11 no longer co-localizes with RabD or the proton pump in cells exposed to hypo-osmotic conditions. Cells attached to coverslips were placed in distilled water for 20 minutes. Cells were fixed and decorated with antibodies to RabD (A), DdRab11 (C) and the proton pump subunit (B,D). Cells were viewed in a fluorescence microscope. White arrows $(A, B)$ show co-localization of RabD and the proton pump. Arrowheads (C,D) show DdRab11 and the proton pump, respectively, not co-localized. The arrow in $\mathrm{D}$ indicates a swollen vesicle in a cell stained for the proton pump. The bright field image of this same cell is shown in E. Scale bar: $5 \mu \mathrm{m}$.
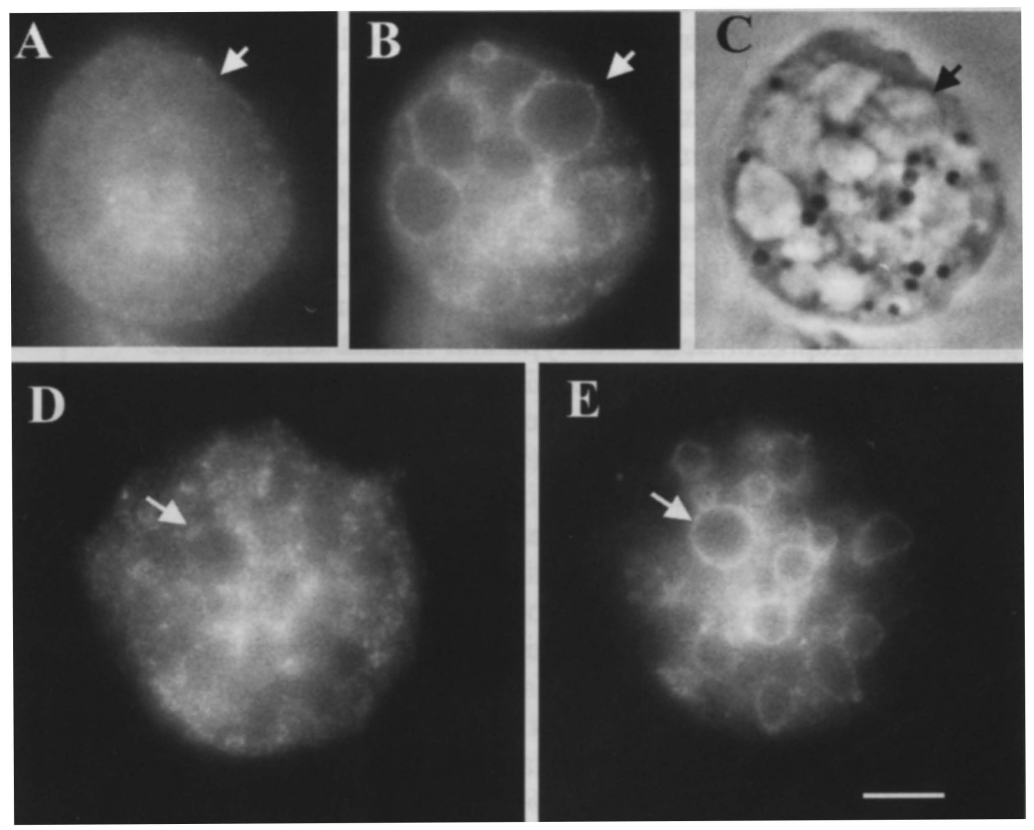

Fig. 9. Both DdRab11 and RabD no longer associates with the proton pump following treatment of cells with the ATPase inhibitor concanamycin A. Cells growing in HL5 medium we exposed to concanamycin A ( $2 \mu \mathrm{M}$ final concentration) for 1 hour, then fixed and prepared for fluorescence microscopy using antibodies to DdRab11 (A), RabD (D) and the $100 \mathrm{kDa}$ proton pump subunit (B,E). Arrows indicate proton pump positive vacuoles that show little staining for DdRab11 or RabD. The cell stained for DdRab11 (A) and $100 \mathrm{kDa}$ proton pump subunit (B) was also photographed under bright field conditions (C). Scale bar: $5 \mu \mathrm{m}$. 
Fig. 10. DdRab11N125I-expressing cells are defective in contractile vacuolar function. Cells expressing a

DdRab11N125I dominant negative protein were generated and contractile vacuolar function was tested. Wild-type (A) and mutant cells (B) grown in growth media were placed in distilled water and photographed. Photomicrographs of wildtype cells in water (A) show cells with
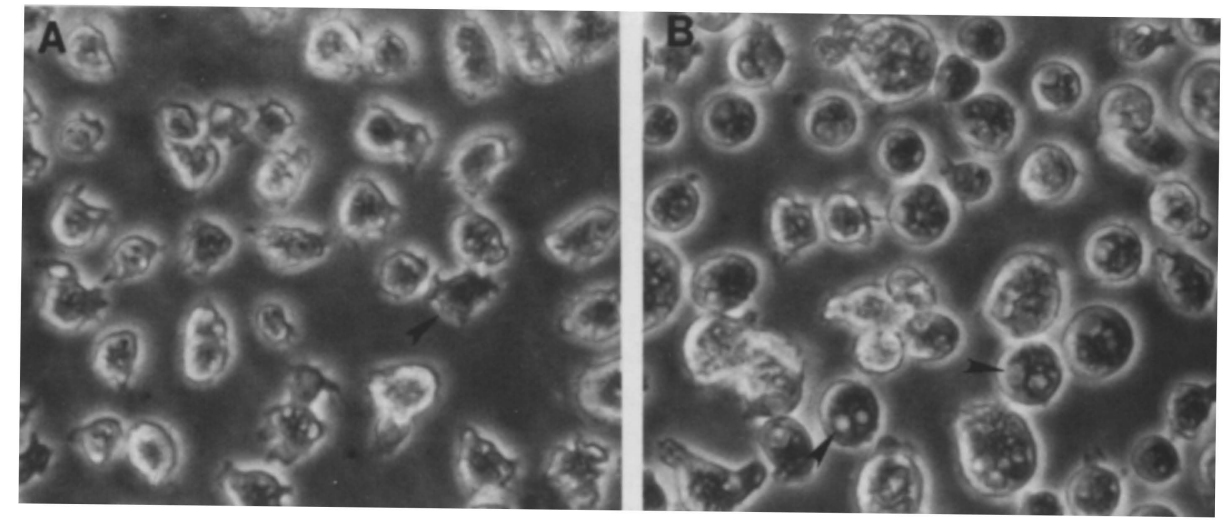

amoeboid morphology and slightly enlarged contractile vacuoles (black arrowhead). However, mutant cells in water (B) were detached from the plastic and contained rounded spherical shapes with distinct enlarged contractile vacuoles (black arrowheads).

(Bush et al., 1996). Furthermore, these mutant cells swell and burst when placed in water, suggesting that the $\mathrm{CV}$ system is no longer functioning normally. Cells expressing DdRab11N125I were subjected to this 'water test'. Exponentially growing shaking suspension cultures of wildtype and mutant cells were allowed to attach to a plastic surface for 15 minutes and then the growth medium was removed, replaced with water and the cells photographed after 15 minutes. Representative phase-contrast photomicrographs of both wild-type and mutant cells after 15 minutes in water are shown in Fig. 10A,B, respectively. After 15 minutes in water, most wild-type cells (Fig. 10A) were attached to the plastic and were amoeboid in shape. However, the mutant cells (Fig. 10B) were rounded and detached from the plastic surface. Many mutant cells also had obvious enlarged and swollen contractile vacuoles (arrowheads). After 2-3 hours, the mutant cells remained swollen and rounded with some lysis of the cells.

To determine whether DdRab11N125I-expressing cell lines demonstrated alterations in the structure of the CV system consistent with altered function, we used indirect immunofluoresence to visualize DdRab11 and the $100 \mathrm{kDa}$ proton pump subunit. Fig. 11 shows representative photomicrographs of both wild-type and mutant cells stained with antibodies to the $100-\mathrm{kDa}$ ATPase protein. The $100 \mathrm{kDa}$ ATPase subunit and in wild-type cells (Fig. 11B) were mainly co-localized as previously shown (Fig. 4). In cells expressing DdRab11N125I, the distribution pattern of the $100 \mathrm{kDa}$ ATPase subunit was strikingly altered. The proton pump protein was found in both bladders and reticular structures, in a pattern similar to control cells; however, the $100 \mathrm{kDa}$ subunit appeared to be concentrated in a thickened and more elaborate reticular network (Fig. 11A). In several cells, enlarged CV bladders were also seen (results not shown). These may represent the previously described large $\mathrm{CV}$ bladders that result from homotypic CV fusions (Fig. 6). The prominence of these enlarged $\mathrm{CV}$ bladders in the mutant cells suggests a role for DdRab11 in exocytosis, shrinking or fission of these structures.

\section{Cells expressing dominant negative DdRab11 appear normal in most but not all endocytic processes}

As described above, DdRab11 associated predominantly with the CV system of membranes with no significant localization
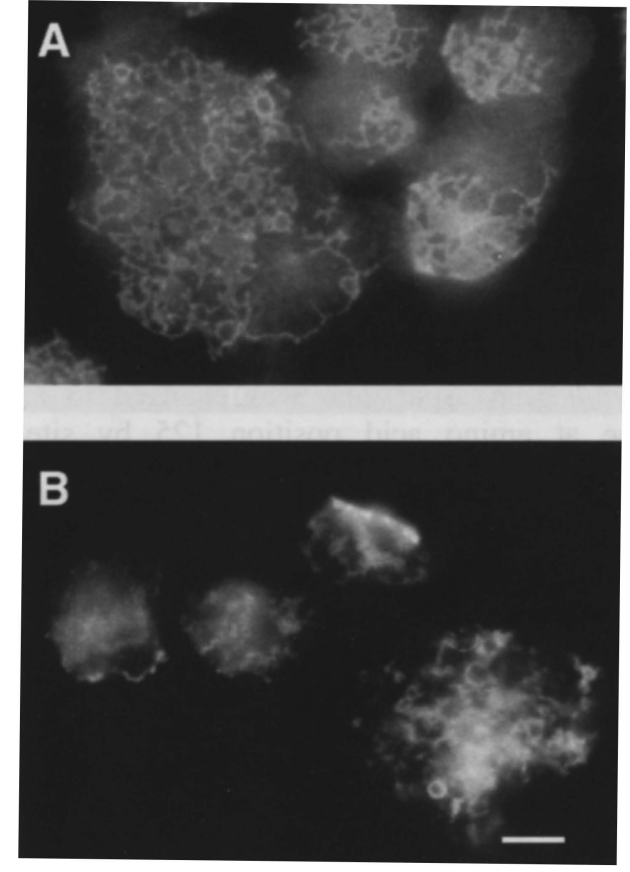

Fig. 11. The reticular network containing the $100 \mathrm{kDa}$ ATPase subunit is altered in cells expressing DdRab11N125I. Mutant and wild-type cells were fixed and stained for the $100 \mathrm{kDa}$ ATPase protein. The distribution of the $100 \mathrm{kDa}$ subunit was altered in mutant cells (A) when compared with the ATPase distribution in wild-type cells (B). Scale bar: $5 \mu \mathrm{m}$.

in the endosomal pathway. This suggests that expression of DdRab11N125I would not affect endocytic processes. Therefore, it was not surprising that the rates of fluid phase uptake (Fig. 12; panel endocytosis) and fluid release (Fig. 12, top) were similar between control and mutant cell-lines. Surprisingly, cells expressing DdRab11N125I internalized particles at twice the rate of control cells (Fig. 12, bottom).

\section{DISCUSSION}

The contractile vacuole system is an osmoregulatory organelle 

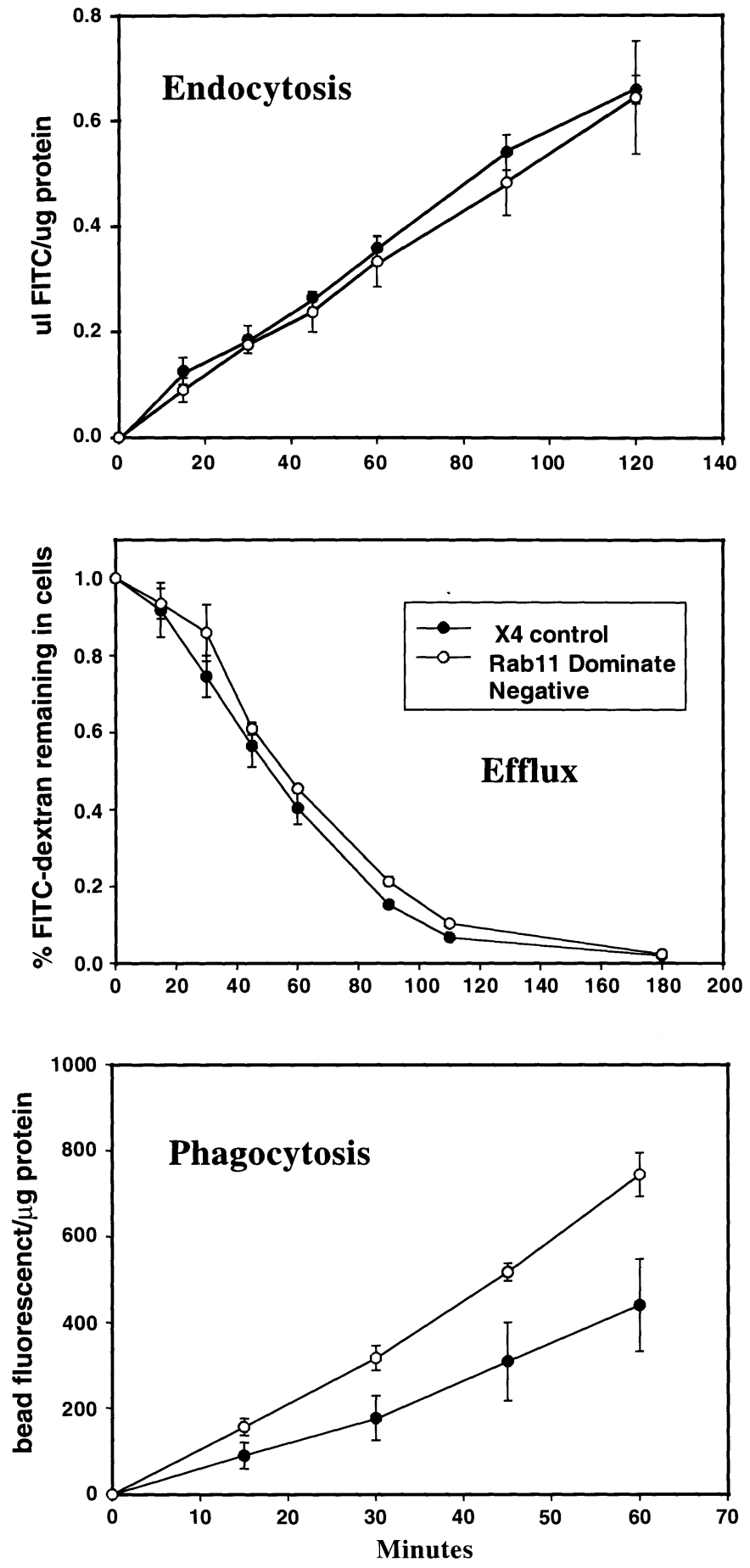

Fig. 12. Cells expressing DdRab11N125I are normal in endocytic uptake and release rates but are enhanced in the rate of phagocytosis. DdRab11N125I (+) cells were incubated in HL5 medium containing FITC-dextran $(1 \mathrm{mg} / \mathrm{ml})$. At the indicated times (top), cells were recovered and washed by centrifugation and accumulated FITCdextran was measured using a spectrophotometer. In addition (middle), after 3 hours of accumulation, cells were washed and resuspended in growth medium. At the indicated times, cells were washed and the FITC-dextran remaining intracellular was measured. Finally (bottom), cells in growth medium were incubated with fluorescent latex beads (at the indicated times), the cells were washed, and accumulated beads were measured using a spectrophotometer. in Dictyostelium that has a bipartite structure consisting of the contractile vacuole and its associated spongiomal collecting ducts (Nolta and Steck, 1994). Relatively little is known concerning how membrane traffic contributes to the formation and function of this organelle, although it has been proposed that the reticular network and bladder interchange by swelling and shrinking (Heuser et al., 1993; Gabriel et al., 1999). As described in this report, $D$. discoideum contains a Rab protein that is highly homologous at the amino acid sequence level to the mammalian Rab11 protein. The Dictyostelium DdRab11encoding gene is expressed at constant levels during the growth and development stages, and Southern blot analysis suggests that a small group of related DdRab11-encoding genes may also exist in this organism. In fact, a DdRab11-like encoding gene has been previously described (Rab11b) but it is much less homologous to mammalian Rab11 (Dragoi and O'Halloran, 1998). Dictyostelium DdRab11 localizes primarily to the $\mathrm{CV}$ organelle and appears to regulate the structure and function of this organelle.

Our results suggest that DdRab11 may be involved in membrane trafficking important in the proper formation and function of the CV. Supporting this conclusion are the observations, based on a variety of approaches, that DdRab11 is greatly enriched and exclusively found in the contractile vacuolar membrane system. This is now the second Rab GTPase, besides RabD, that is enriched in the contractile vacuole system that appears to regulate membrane flow in and out of this system. Cell lines overexpressing DdRab11N125I protein displayed a functional defect in their water homeostasis, and displayed morphological alterations in their contractile vacuolar membrane structure. Taken together, these results indicate that the $\mathrm{CV}$ system needs to regulate membrane flow to maintain its normal morphological status and this flow is regulated by at least two Rab proteins (DdRab11 and RabD).

DdRab11 is associated with contractile vacuoles that are undergoing water expulsion, contractile vacuoles that are newly forming and contractile vacuoles that are undergoing homotypic fusions; DdRab11 may regulate one or more of these processes. Supporting this idea are data that reveal the presence of enlarged contractile vacuolar structures in cells expressing DdRab11N125I. These structures are most likely homotypically fused contractile vacuole bladders that have not undergone proper formation/deformation. These very large contractile vacuole bladders are usually not seen in wild-type cells under the same conditions. In addition, the data from the 'water test' on these mutant cells suggests that DdRab11 functions in vesicle expulsion. The mutant cells swell, round up and float off a flat surface. They also have very prominent enlarged contractile vacuoles as seen by light microscopy.

As reported here, DdRab11 is localized almost exclusively in the CV network. In addition, we were not able to detect DdRab11 in magnetically fractionated endosomal/lysosomal membranes (Fig. 2), and endocytosis and efflux were not altered in DdRab11N125I cell lines. However, on rare occasions, we see DdRab11 associated with fluid phase markers (Fig. 4). These data suggest that on unique occasions some interaction between the two compartments takes place and DdRab11 is briefly associated with fused elements of the endosomal and contractile vacuolar systems. Alternatively, DdRab11-containing membranes may associate with the endolysosomal system via formation of autophagosomes. 
The role of Rab11 appears diverse, but in many mammalian cell types this Rab may be involved in the transport of vesicles to the cell surface. For example, Rab11 is associated with the recycling compartments that contain transferrin in K562 cells and has been found to regulate recycling through the pericentriolar recycling endosome in $\mathrm{CHO}$ and BHK cells (Green et al., 1997; Ren et al., 1998; Ullrich et al., 1996). Besides functioning in the endosomal system, in gastric parietal cells Rab11 is found in immunoisolated $\mathrm{H}^{+} / \mathrm{K}^{+}$ATPase-containing tubulovesicles, and may be involved in the function of these tubulovesicles in apical regulated vesicle fusion (Urbe et al., 1993). Rab11 has also been shown to be associated with secretory vesicle transport in mammalian cells (Calhoun et al., 1998; Calhoun and Goldenring, 1996).

The almost exclusive CV localization of DdRab11 in Dictyostelium would seem to eliminate an important role for this protein in endosomal recycling. Consistent with this, fluid phase trafficking proceeds in a linear fashion from small pinosomes and macropinosomes to endosomes, then lysosomes and finally moving through a large post-lysosomal vesicle population to be secreted via exocytosis. It has been reported that the contractile vacuolar and endosomal membrane systems are separate and do not communicate with each other via vesicle trafficking (Gabriel et al., 1999; Becker et al., 1999), even though RabD and the proton pump are apparently localized to both systems (Heuser et al., 1993; Bush et al., 1994). However, it has recently been demonstrated that internalized plasma membrane proteins are rapidly recycled back to the cell surface (Neuhaus and Soldati, 2000) and at least two of these plasma membrane proteins appear to recycle through the $\mathrm{CV}$ network (E.H. and J.C., unpublished). Furthermore, in a study by the Gerisch group (Gabriel et al., 1999), fluorescent fluid phase markers were used to visualize the endosomal system, and the authors correctly concluded that no fluid phase was ever found in the $\mathrm{CV}$ network (visualized with GFP-dajumin). Except for the use of Cy-3-tagged cell surface proteins (Cy-3 can be cleaved in endo-lysosomes), no attempt was made to analyze the distribution of specific internalized plasma membrane proteins. One of the functions of DdRab11 therefore could be to regulate the movement of bladder membranes and perhaps a subset of plasma membrane proteins to the cell surface from the CV network. In fact, the CV network may be an organelle that possibly is an evolutionary precursor to the recycling endosomal system in higher eukaryotic systems. Another possibility could be that as eukaryotic cellular evolution progressed, the loss of a needed osmoregulation system in multicellular organisms led to a conservation of the Rab11 function of directing membrane transport from recycling membrane compartments to the plasma membrane (endosomal system recycling).

Sheff et al. have reported that in polarized epithelial cells, Rab4 was enriched in early endosomes while DdRab11 was enriched in recycling endosomes (Sheff et al., 1999). These authors report physical separations of the two compartments of the endosomal system and that the two Rab proteins are involved in the separate functional endosomal compartments. This physical separation is also seen in Dictyostelium. RabD (Rab4-like) is localized in endosomal/lysosomal membranes and contractile vacuolar spongiumal vesicles whereas the DdRab11 protein is associated only with the CV system. This separation is probably because of the different functional nature of the two Rab proteins. Expression of dominanat negative
RabD results in the formation of a patch of $\mathrm{CV}$ membrane at the cell surface and defects in the endosomal system (Bush et al., 1996), including a reduction in the fusion of lysosomes to generate post-lysosomes. By contrast, expression of DdRab11N125I results in the formation of swollen CV reticular elements with no obvious changes in the CV system.

Although immunofluorescence microscopy images suggest that RabD and DdRab11 co-localized to the same CV elements, immuno-electron microscopy will be needed for confirmation. In fact, based on the differential response of these two Rab proteins to changes in osmolarity, it is possible that they associate preferentially with different subcompartments of the CV. This type of association of different Rabs to different subcompartments of the same organelle has already been observed for mammalian Rab4, Rab5 and hRab11 (Sonnichsen et al., 2000). It was also intriguing that DdRab11 no longer colocalized with the proton pump or RabD in cells subjected to hypo-osmotic conditions. This could mean that Rab11 functions to regulate water efflux under normal conditions but no longer functions on extreme hypo-osmotic conditions. Alternatively, the small Rab11-positive vesicles observed at the cell surface of cells suspended in hypo-osmotic environment might be involved in trafficking water out of cells.

It is interesting that cells overexpressing DdRab11N125I protein have a higher rate of phagocytosis than do wild-type cells. This is in direct contrast to the situation observed in mammalian macrophages. Cox et al. have reported that expression of a GTP binding-deficient Rab11 protein in macrophages decreased transferrin recycling and phagocytosis, implying that in mammalian cells Rab11 may regulate transport of membrane from recycling endosomes to the forming phagocytic cup (Cox et al., 2000). Expression of DdRab11N125I resulted in the accumulation of swollen CV reticulum, suggesting that DdRab11 may regulate the level of membrane in the reticular elements of the CV. If the reticular elements of the $\mathrm{CV}$ contributed membrane to the forming phagocytic cup, then an increase in this pool of membranes would be predicted to increase the rate of phagocytosis. Another possibility is that a shared effector protein exists between the contractile vacuolar and phagocytic systems, and that the dominant negative DdRab11 protein is 'soaking up' this effector resulting in a reduction in the rate of phagocytosis.

In this study, we present evidence that DdRab11 associates almost exclusively with the CV system of membranes, including both reticular elements and bladder membranes. In addition, it appears that DdRab11 may regulate membrane traffic to or from the $\mathrm{CV}$, and, along with at least one other $\mathrm{Rab}$, appears to be crucial in the formation of an organelle important in osmotic regulation and perhaps recycling of internalized membrane proteins back to the cell surface.

We thank Dr Maurice Kleve for his expert technical assistance. A Careers Grant from the National Science Foundation (MCB-973409) and a start-up grant from the Arkansas Science and Technology Association (ASTA) awarded to J.M.B. provided support for this work. J.C. was supported by a grant from the NIH DK39232.

\section{REFERENCES}

Becker, M., Matzner, M. and Gerisch, G. (1999). Drainin required for 
membrane fusion of the contractile vacuole in Dictyostelium is the prototype of a protein family also represented in man. EMBO J. 18, 3305-3316.

Buczynski, G., Bush, J. Zhang, L., Rodriguez-Paris, J. and Cardelli, J. (1997). Evidence for a recycling role for Rab7 in regulating a late step in endocytosis and in retention of lysosomal enzymes in Dictyostelium discoideum. Mol. Biol. Cell 8, 1343-1360.

Bush, J. and Cardelli, J. (1993). Molecular cloning and DNA sequence of a Dictyostelium cDNA encoding a Ran/TC4 related GTP binding protein belonging to the Ras superfamily. Nucleic Acids Res. 21, 1675.

Bush, J., Franek, K., Daniels, J., Spiegelman, G., Weeks, G. and Cardelli, J. (1993). Cloning and characterization of three novel Dictyostelium discoideum Rab family genes and two genes related to human Rab-1. Gene 136, 55-60.

Bush, J., Nolta, K., Rodriguez-Paris, J., Ruscetti, T., Temesvari, L., Steck, T. and Cardelli, J. (1994). A Rab4-like GTPase colocalizes with V-H(+) ATPases in extensive reticular elements of the contractile vacuoles and lysosomes in Dictyostelium discoideum. J. Cell Sci. 107, 2801-2812.

Bush, J. and Cardelli, J. (1995). Rab and Rho proteins in Dictyostelium discoideum. In Guidebook to the Small GTPases (ed. M. Zerial, L. Huber and J. Tooze), pp. 385-390. New York: Oxford Univeristy Press.

Bush, J., Temesvari, L., Rodriguez-Paris, J., Buczynski, G. and Cardelli, J. (1996). A role for a Rab4-like GTPase in endocytosis and in regulation of contractile vacuole structure and function in Dictyostelium discoideum. Mol. Biol. Cell. 7, 1623-1638.

Calhoun, B. and Goldenring, J. (1996). Rab proteins in gastric parietal cells: evidence for the membrane-recycling hypothesis. Yale J. Biol. Med. 69, 1 8.

Calhoun, B. C., Lapierre, L. A., Chew, C. S. and Goldenring, J. R. (1998). DdRab11 redistributes to apical secretory canaliculus during stimulation of gastric parietal cells. Am. J. Physiol. 275, C163-C170.

Cox, D., Lee, D., Dale, B., Calafat, J. and Greenberg, S. (2000). A DdRab11-containing rapidly recycling compartment in macrophages that promotes phagocytosis. Proc. Natl. Acad. Sci. USA 97, 680-685.

Daniels, J., Bush, J., Cardelli, J., Spiegelman, G. and Weeks, G. (1994). Isolation of two novel Ras genes in Dictyostelium discoideum; evidence for a complex developmentally regulated Ras gene subfamily. Oncogene $\mathbf{9 , 5 0 1 -}$ 509.

Dragoi, I. and O'Halloran T. (1998). Cloning and characterization of a Dictyostelium gene encoding a small GTPase of the Rab11 family. J. Cell Biochem. 70, 29-37.

Gabriel, D., Hacker, U., Kohler, J., Muller-Taubenberger, A., Schwartz, J. Westphal, M. and Gerisch, G. (1999) The contractile vacuole network of Dictyostelium as a distinct organelle: its dynamics visalized by a GFP marker protein. J. Cell Sci. 112, 3995-4005.

Green, E., Ramm, E., Riley, N., Spiro, D., Goldenring, J. and WesslingResnick, M. (1997). DdRab11 is associated with transferrin-containing recycling compartments in K562 cells. Biochem, Biophys. Res. Commun. 239, 612-616.

Hall, A. (1993). Ras-related proteins. Curr. Opin. Cell Biol. 5, 265-268.

Heuser, J., Zhu, Q. and Clarke, M. (1993). Proton pumps populate the contractile vacuoles of Dictyostelium discoideum. J. Cell Biol. 121, 13111327.
Maniak, M. (2001). Fluid-phase uptake and transit in axenic dictyostelium cells. Biochim. Biophys. Acta 1525, 197-204.

Manstein, D., Schuster, H., Morandini, P. and Hunt, D. (1995). Cloning vectors for the production of proteins in Dictyostelium discoideum. Gene 162, 129-134.

Mellman, I. (1994). Membranes and sorting. Curr. Opin. Cell Biol. 6, 497498.

Nolta, K. and Steck, T. (1994). Isolation and initial characterization of the bipartite contractile vacuole complex from Dictyostelium discoideum. J. Biol. Chem. 269, 2225-2233.

Neuhaus E. M. and Soldati T. (2000) A myosin I is involved in membrane recycling from early endosomes. J. Cell Biol. 150, 1013-1026.

Nuoffer, C. and Balch, W. (1994). GTPases: Multifunctional molecular switches regulating vesicular traffic. Annu. Rev. Biochem. 63, 949-990.

Ren, M., Xu, G., Zeng, J., De Lemos-Chiarandini, C., Adesnik, M. and Sabatini, D. (1998). Hydrolysis of GTP on Rab11 is required for the direct delivery of transferrin from the pericentriolar recycling compartment to the cell surface but not from sorting endosomes. Proc. Natl. Acad. Sci. USA 95, 6187-6192.

Rodrigeuz-Paris, J., Nolta, K. and Steck, T. (1993). Characterization of lysosomes isolated from Dictyostelium discoideum by magnetic fractionation. J. Biol. Chem. 268, 9110-9116.

Rupper, A. and Cardelli, J. (2001) Regulation of phagocytosis and endophagosomal trafficking pathways in Dictyostelium discoideum. Biochim. Biophys. Acta 1525, 205-216.

Sambrooke, J., Fritsch, E. and Maniatis, T. (1989) Molecular Cloning: A Laboratory Manual. 2nd edn. Cold Spring Harbor, NY: Cold Spring Harbor Laboratory Press.

Sesaki, H., Wong, E. and Siu, C. (1997). The cell adhesion molecule DdCAD-1 in Dictyostelium is targeted to the cell surface by a nonclassical transport pathway involving contractile vacuoles. J. Cell Biol. 138, 939951.

Sheff, D., Daro, E., Hull, M. and Mellman, I. (1999). The receptor recycling pathway contains two distinct populations of early endosomes with different sorting functions. J Cell. Biol. 5, 123-139.

Sonnichsen B., De Renzis S., Nielsen E., Rietdorf J. and Zerial M. (2000) Distinct membrane domains on endosomes in the recycling pathway visualized by multicolor imaging of Rab4, Rab5, and Rab11. J. Cell Biol. 149, 901-914

Temesvari L., Rodriguez-Paris J., Bush J., Zhang L. and Cardelli J. (1996). Involvement of the vacuolar proton-translocating ATPase in multiple steps of the endo-lysosomal system and in the contractile vacuole system of Dictyostelium discoideum. J. Cell Sci. 109, 1479-1495.

Ullrich, O., Reinsch, S., Urbe, S., Zerial, M. and Parton, R. (1996). Rab11 regulates recycling through the pericentriolar recycling endosome. J. Cell Biol. 135, 913-924.

Urbe, S., Huber, L., Zerial, M., Tooze, S. and Parton, R. (1993). Rab11, a small GTPase associated with both constitutive and regulated secretory pathways in PC12 cells. FEBS Lett. 334, 175-182.

Zhu Q., Liu T. and Clarke M. (1993) Calmodulin and the contractile vacuole complex in mitotic cells of Dictyostelium discoideum. J. Cell Sci. 104, 11191127. 